\title{
PROCESSO INTERNACIONAL TRANSFRONTEIRIÇO: OS LITÍGIOS QUE NÃO RESPEITAM FRONTEIRAS - DA SOBERANIA À TUTELA DOS DIREITOS
}

\author{
WHY RESIST? THE STF RESISTANCE TO JUDICIAL DIALOGUE WITH \\ CORTEIDH.
}

\author{
${ }^{1}$ Valesca Raizer Borges Moschen \\ ${ }^{2}$ Graziela Argenta Zaneti
}

\section{RESUMO}

Proponho uma reflexão a respeito do processo internacional transfonteiriço através da passagem da soberania para a tutela dos direitos, como fim do proc. civil no Estado Democrático Constitucional. Esta mudança de paradigma é expressa no novo CPC L 13.105 115 , art. $3^{\circ}, 4^{\circ}$ e $6^{\circ}$, aplicáveis ao processo internacional. Nesta nova visão, a cooperação jurídica internacional, na modalidade de auxílio direto, é excelente instrumento para implementação do novo paradigma e deve ser considerada como estratégia fundamental à efetivação dos direitos em litígios que não respeitam fronteiras e que ocorrem ao mesmo tempo em dois ou mais territórios soberanos.

Palavras-chave: Processo internacional, Litígio transfonteiriço, Tutela dos direitos, Cooperação, Auxílio direito

\section{INTERNATIONAL CIVIL PROCEDURE AND CROSS-BORDER LITIGATION: DISPUTES THAT DO NOT RESPECT BORDERS - SOVEREIGNTY V. RIGHTS PROTECTION}

\begin{abstract}
I propose a reflection on the international border process regarding the paradigm shift of sovereignty as the center of the concerns of the international procedural law for the protection of effectively rights, timely and appropriate brought to the end of the civil procedure in the State Constitutional Democratic and expressed in the new Civil Procedure Code (Law 13.105/2015) in art. $4^{\circ}$ and $6^{\circ}$, contained in Chapter 1 - Of the Fundamental Rules of Civil Procedure. In this new vision of international procedural law, international legal cooperation in modality of direct aid is excellent tool for implementation of the new paradigm.
\end{abstract}

Keywords: International civil procedure, Cross-border litigation, Rights protection, Judicial cooperation, Direct aid

\footnotetext{
${ }^{1}$ Doutora em Direito e Relações Internacionais pela Universidade de Barcelona - UB, Barcelona, (Espanha). Professora e coordenadora do Programa de Pós-Graduação em Direito - UFES, PPGDIR, Vitória, ES. (Brasil). E-mail: raizervalesca@gmail.com.

${ }^{2}$ Especialista em Direito Urbanístico e Ambientall pela Fundação Escola Superior do Ministério Público FESMP_PPROV, Mato Grosso, MT. (Brasil). Promotora de Justiça do Ministério Público do Estado do Espírito Santo - MPES, Espirito Santo - ES. (Brasil). E-mail: gargenta@ mpes.mp.br.
} 


\section{INTRODUÇÃO}

Este trabalho procura introduzir, à luz da nova legislação processual brasileira, o tema dos litígios transfronteiriços. Uma sociedade em vias de expansão não pode deixar de analisar o tema da tutela de direitos para além dos limites que marcam as suas fronteiras. Danos ambientais, tutela do consumidor, falências e recuperações de empresa, crimes de colarinho de colarinho branco, lavagem de dinheiro e a disciplina da probidade administrativa implicam a necessidade de trocas de informações e de decisões de forma efetiva e tempestiva, inclusive para a satisfação dos direitos, sem que possa ser alegada a soberania como elemento de limite ou controle a esta finalidade.

O Novo Código de Processo Civil (Lei 13.105/2015) ampliou a disciplina do processo civil internacional. Isso ocorreu porque o NCPC tratou dos temas clássicos, tais como jurisdição nacional em relação aos litígios e às decisões estrangeiras, matéria denominada pelo CPC de 1973 de competência internacional, e agora chamada de limites à jurisdição nacional (art. 21 a 25 do CPC/2015), reconhecimento das sentenças e decisões estrangeiras (art. 960 a 965 do CPC/2015), e, para além disto, criou uma extensa disciplina para a cooperação judicial internacional, tratando da divisão de trabalho entre juízes e tribunais de diversos Estados-nação (art. 26 a 41 do CPC/2015).

Não há no NCPC, contudo, nenhuma menção aos litígios transfronteiriços.

A globalização, a mundialização e os processos de fluxos de pessoas, bens e serviços contribuíram para a ampliação do ambiente jurídico para além das fronteiras nacionais, permitindo a ruptura, se não teórica, pelo menos fática, dos antigos dogmas que ligavam a soberania ao problema da distribuição da competência judicial entre Estados-nação. Contudo, apesar da realidade fática dos acidentes ambientais transfronteiriços, dos danos aos consumidores ocorridos em mais de um país simultaneamente através da internet ou de outros meios de comércio e consumo internacional, e de outras situações análogas, como as já regulamentadas no caso das falências transfronteiriças, a exemplo da Convenção de New York e da União Europeia, a dogmática processual civil clássica e os tribunais brasileiros ainda estão presos aos conceitos estatalistas de jurisdição e competência, negando tutela aos direitos. 
A proposta de trabalho visa possibilitar a reflexão, a partir dos litígios transfonteiriços, de que as finalidades estabelecidas pelo NPCP, quais sejam a tutela dos direitos efetiva, tempestiva e adequada, também permeiam o processo internacional tranfonteiriço, e, dessa forma, a escolha e a interpretação adequada dos institutos são essenciais para tal fim, visão esta que encontra-se dentro do contexto processualístico em destaque nestes últimos anos, consistente na tutela dos direitos fundamentais ambientais e dos direitos humanos (tutela dos direitos) para além das fronteiras nacionais.

A análise dos elementos normativos que o novo Código de Processo Civil prescreve faz-se importante para a construção de uma dogmática do processo civil transfronteiriço.

\section{A TUTELA DOS DIREITOS COMO FIM DA JURISDIÇÃO E DO PROCESSO}

Os problemas decorrentes dos limites à jurisdição nacional (previstos no NCPC nos arts. 21 ao 25) e da cooperação internacional (arts. 26 a 41 do NPCP) em litígios transfronteiriços, como nos demais litígios transnacionais, estão diretamente relacionado à formação dos Estados-nação e à ligação ocorrida na época de sua formação entre território, unidade do direito e poder absoluto do monarca, identificados com a noção de soberania. A soberania passou a reger as relações internacionais e a jurisdição foi identificada como seu atributo indeclinável e indelegável (CHIOVENDA, 1943).

Atualmente as questões não se colocam mais na perspectiva do Estado-nação, mas do Estado Democrático Constitucional, no âmbito interno, e da tutela dos direitos humanos, no âmbito internacional. O Processo Civil Internacional deve ser utilizado para a resolução de tais questões, visando a tutela dos direitos, para a efetivação do Direito Internacional Privado voltado para este fim, com o objetivo de "encontrar um ponto de equilíbrio, de modo a permitir que o direito interno seja soberano, mas também capaz de regrar os fatos que extrapolam os limites territoriais do Estado" (PERLINGEIRO, 2014, p. 1).

Nos limites à jurisdição nacional, utilizam-se de critérios de conexão com o território nacional, que poderão se referir à pessoa dos sujeitos da relação jurídica (v.g., nacionalidade, domicílio, residência), ao ato ou fato jurídico per se (v.g., lugar da celebração do contrato, lugar da prática do fato gerador da responsabilidade civil) ou à situação da coisa objeto do negócio jurídico (v.g., aplicação da lex rei sitae em litígios sobre direitos reais) (LIMA PINHEIRO, 2002, p. 20). Essas normas podem ser tanto unilaterais, estabelecidas pelo próprio Estado- 
nação, quanto multilaterais, estabelecidas por mais de um Estado-nação em acordos, tratados e convenções internacionais.

$\mathrm{Na}$ definição de limites à jurisdição nacional há, nas hipóteses de jurisdição concorrente (art. 21 e 22 do NCPC), a possibilidade de busca da solução de definição de jurisdição com vistas a tutela dos direitos, e não de forma arbitrária, com olhos apenas no respeito à soberania como valor fim do processo civil internacional (MOSCHEN; GUERRA, 2009; MOSCHEN; LOMEU, 2013; MOSCHEN; ZANETI, 2015).

Nos litígios transfonteiriços, comuns nos direitos coletivos pela característica da indivisibilidade de seu objeto, as jurisdições, em regra, são concorrentes entre diferentes ordenamentos jurídicos.

Os princípios regentes para definição da jurisdição competente para tutelar determinado caso em concreto podem ser identificados a partir: (1) da proximidade com a situação objeto de análise; (2) da eficácia prática da decisão, (3) da distribuição harmoniosa da competência; e (4) da autonomia da vontade (FERRER CORREIA, 2000).

Conforme explica LUPOI (2002), estes princípios devem ser coordenados com as cláusulas de exceção de competência, a exemplo do forum non conveniens, de modo a se buscar uma coordenação jurisdicional internacional voltada para a competência adequada, isto é: julga quem tem melhor condições de tutelar o direito. (DIDIER JR.; ZANETI JR., 2014, p. 105$107)^{1}$.

Lima Pinheiro (2002, p. 26) esclarece que, diante de normas de conflitos e de situações que envolvam mais de um sistema normativo, o direito aplicável é denominado de jus. Nesse sentido, o autor refere que "[...] as normas de conflitos de Direito Internacional Privado são proposições que perante uma situação em contacto com uma pluralidade de sociedades estaduais determinam o Direito aplicável"

Nem sempre forum e jus apresentam-se correspondentes, conforme acentua a doutrina, assim existe a possibilidade de o Estado ter interesse na apreciação de uma situação pelos seus tribunais sem que, contudo, exista uma conexão suficiente para aplicação de suas normas materiais.” (ZANETI JR; BORGES; CARDOSO, no prelo).

A jurisdição, no aspecto interno (doméstico), pode ser compreendida no conceito de jurisdição estatal de Chiovenda, ou seja, como mecanismo estatal de resolução de conflitos dentro de determinado território, ou seja, dentro do Estado-nação. Atuando o juiz-estatal, como

\footnotetext{
${ }^{1} \mathrm{Na}$ doutrina, defende-se o princípio da competência adequada para os processos coletivos, partindo da premissa que cada juiz é juiz de sua própria competência, Kompetenzkompetenz.
} 
terceiro imparcial, funcionário do Estado, substituindo as partes interessadas, para a aplicação da lei ao caso concreto.

A jurisdição, no aspecto internacional, por sua vez, conforme explica Afonso Rodrigues Queiró (1979), pode ser entendida como elemento de soberania do Estado ou como competência de um ente para julgar demandas dotadas de elementos de direito internacional. Assim, nesta última acepção, a jurisdição internacional significaria, em linhas gerais, o poder atribuído aos estados para exercer em seus respectivos territórios suas funções executivas, legislativas e judiciárias, em conformidade com o direito internacional. Utilizaremos o termo jurisdição na segunda acepção, ou seja, como competência de um ente para julgar demandas dotadas de elementos de direito internacional.

Não é só o conceito de jurisdição no aspecto internacional que exige uma mudança de paradigma com vistas à tutela dos direitos como fim do processo civil internacional, mas também o conceito de jurisdição de Chiovenda no aspecto interno passa por uma atualização em curso. Isso implica reconhecer que o Estado está deixando de figurar como parte central da acepção de jurisdição, tanto no processo civil internacional, quanto no interno. Neste sentido, também deverá ser revisada a doutrina brasileira mais conservadora (MESQUITA, 1988, p. 5171).

Portanto, a concepção de jurisdição como função do Estado (CHIOVENDA, 1943, p. 11), que tem como escopo a atuação da vontade concreta da lei por meio da substituição, pela atividade de órgãos públicos, da atividade de particulares ou de outros órgãos públicos, já no afirmar a existência da vontade da lei, já no torná-la, praticamente, efetiva, contradiz, assim, os alicerces teóricos do Estado Democrático Constitucional contemporâneo. A concepção de jurisdição não pode ser mais concebida como de função exclusiva do Estado, como atestam a arbitragem, as convenções processuais e os demais meios alternativos de resolução de controvérsias, e muito menos, de função exclusivamente voltada para os interesses do Estado. O fim do processo civil é a tutela dos direitos (MARINONI, 2006, p. 21-139; MITIDIERO, 2014, p. 51-74).

\section{CONTORNOS DOS LITÍGIOS TRANSFONTEIRIÇOS, EM ESPECIAL NO MEIO AMBIENTE}

No universo do processo civil internacional, há litígios, cujas peculiaridades, tornamos ainda mais difíceis para a adequada tutela dos direitos, em razão de os danos ou ilícitos 
ocorrerem simultaneamente em mais de um ordenamento jurídico, sem respeitar as fronteiras dos respectivos Estados-nação - são os chamados litítigos transfonteiriços (JOSEPH, 2004)².

Para estas espécies de litígios, a escolha do meio mais adequado para a tutela do direito é assaz importante, bem como a clareza dos fins algemados pelo processo, qual seja a tutela dos direitos efetiva (tem que se realizar no mundo real), tempestiva (que venha em tempo razoável) e adequada (ao direito material que irá versar).

Estes são as principais objetivos definidos no NCPC para o processo civil, os quais devem permear inclusive o processo civil internacional, flexibilizando, de certa forma, a soberania como pilar do direito processual internacional. Não se trata de pregar a unificação do direito processual internacional, sua uniformização ou sua harmonização (SILVA NETO, 2003, p. 55-57; KRAMER; RHEE, 2012; UZELAC, 2014), mas de compreender que, no Estado Democrático de Direito, as instituições e o direito justificam-se na tutela dos direitos, e não mais prioritariamente e somente na soberania. A soberania deve ceder diante de outros valores constitucionais, em especial quando ela é entrave à tutela dos direitos fundamentais.

Os danos ambientais transfronteiriços revelam-se, atualmente, como uma temática emergente também no Direito Internacional do Meio Ambiente. Isto ocorre, em razão dos problemas identificados, tanto no Direito Internacional Público (relação entre os Estados), quanto no Direito Internacional Privado (relação entre os cidadãos, os Estados - enquanto entes responsáveis civilmente - e as empresas) no que diz respeito à resolução dos acidentes ambientais com a tutela dos Estados, sem prejuízos às vítimas, que, neste caso, encontram-se em diferentes Estados e, consequentemente, estão submetidas a diferentes regimes jurídicos, mas merecem igual tutela dos direitos.

Um exemplo que pode auxiliar na compreensão do litígio transfonteiriço é o seguinte: imaginemos um dano ambiental ocorrido na fronteira do Uruguai e Brasil. Nosso ordenamento jurídico prevê tutela condenatória dos direitos difusos; entretanto, no direito uruguaio, não há previsão de tutela condenatória in pecúnia. Assim, parcela do dano ficará sem reparação, caso não existam mecanismos de cooperação judicial e reconhecimento das decisões brasileiras pelo Estado Uruguaio capazes de tornarem efetiva a tutela integral e erga omnes do direito ambiental, que é, em essência, indivisível, pois trata-se de um só meio ambiente, de um só ecossistema.

\footnotetext{
${ }^{2}$ Neste sentido, importante notar que uma série de casos de lesões à direitos humanos, envolvendo corporações multinacionais como Nike, Shell, Coca-Cola, entre outras, foram admitidos em países como os Estados Unidos, Inglaterra e Austrália.
} 
O tema, no direito internacional público, ligado à responsabilidade dos Estados, vem sendo discutido na International Law Comission, com a abertura dos sistemas nacionais para a tutela de danos transfronteiriços (dissociada da responsabilização internacional dos Estados), a exemplo dos EUA e da União Européia, e regulamentação pelas Convenções de Responsabilidade Civil por danos causados por hidrocarbonetos e por danos nucleares, ocorrendo, gradativamente, o fortalecimento do princípio do poluidor-pagador, com vistas a se atender ao princípio do tratamento não discriminatório entre litigantes vítimas de uma catástrofe ambiental de origem comum, que supere as fronteiras estatais.

Assim, pode-se dizer que três são os pontos mais importantes para definir o processo transfronteiriço e para a adequada tutela dos direitos para além dos territórios nacionais: a) “danos ambientais transfronteiriços"; b) “litígios transfronteiriços" e c)"processo internacional transfronteiriço para tutela de direitos coletivos - processo coletivo transfronteiriço" (ZANETI JR; BORGES; CARDOSO, no prelo). A estes pontos está conectado o conceito de jurisdição.

Antes de mais nada, é preciso diferenciar entre os litígios transnacionais em sentido estrito e os litígios transfronteiriços. Christian Von Bar (1999, p. 303) define a ocorrência de responsabilidade ambiental com contornos internacionais sempre que o incidente afetar mais de um Estado-nação, o que deriva de duas situações: 1) quando o meio atingido (v.g., água, atmosfera) não respeita fronteiras e; 2) quando as partes envolvidas são multinacionais, filiais/agentes de empresas estrangeiras ou associados a empresas estatais, a gerar discussão acerca da responsabilidade da empresa controladora estrangeira, usufrutuária econômica do risco assumido. Também se inclui nessa classificação os afetados multinacionais pelo dano.

Assim, na hipótese 1), teremos um dano ambiental transfronteiriço; na hipótese 2), um dano ambiental que poderá ensejar um litígio transnacional, especialmente no que diz respeito à necessidade de atuação judicial por carta rogatória, reconhecimento de decisões e sentenças estrangeiras e execução em território estrangeiro; este dano, contudo, não apresentará as características transfronteiriças, caso as consequências do dano não ultrapassem as fronteiras do país de origem.

Diante disso, pode-se dizer que, nem todo litígio ambiental transnacional, será resultante de dano transfronteiriço. Embora, muito provalvemente os danos transfronteiriços, serão danos transnacionais e coletivos. Utilizamos o exemplo privilegiado do dano ambiental porque este possui inegável caráter úbiquo, em decorrência de sua capacidade de dispersão, não respeitando fronteiras. É o que ocorre nos casos de "poluição (danos ambientais) transnacional 
(is)" e "responsabilidade ambiental internacional", conceitos que se complementam, quando ocorrem simultaneamente em mais de um ordenamento jurídico (ZANETI JR; BORGES; CARDOSO, no prelo).

Para imputar a responsabilidade ao agente causador do dano, a responsabilidade será, necessáriamente, uma ação judicial dotada de elementos de internacionalidade (LUPOI, 2002, p. 3 e ss) ${ }^{3}$ - ação transnacional ${ }^{4}$ (WHYTOCK, 2011, p. 96) que, por sua vez, poderá ser ou não processada de forma coletiva.

Os modelos de tutela coletiva ${ }^{5}$ (GRINOVER; WATANABE; MULLENIX, 2014) (MONASTIER, 2011) (BASSET, 2003, p. 42) devem ser enquadrados dentro do conceito geral proposto pela doutrina, conforme Fredie Didier Jr e Hermes Zaneti Jr. (2014, p. 38-39): "processo coletivo é aquele em que se postula um direito coletivo lato sensu (situação jurídica coletiva ativa) ou se afirma a existência de uma situação jurídica coletiva passiva”. Este conceito permite a compreensão do objeto litigioso da demanda (causa de pedir e pedido), independentemente do modelo jurídico em que este se apoia, seja a Ação Coletiva do modelo brasileiro, sejam as Class Actions norte-americanas (GIDI, 2007) ou sejam as ações agregadas ou a Verbandsklag ou Musterverfahren da experiência alemã (MENDES, 2002, p. 121 e ss) (modelo predominante na Europa-Continental).

Diante disso, pode dizer que a mudança de paradigma no processo civil internacional da soberania à tutela dos direitos como fim perquirido faz-se ainda mais necessária diante dos litígios transfronteiriços, em razão da sua peculiaridade de ocorrerem simultaneamente em diferentes jurisdições, não sendo mais suficiente a análise, em tais casos, do problema com a visão estrita da soberania, sob pena de prejuízo à tutela dos direitos efetiva, tempestiva e adequada, eis que escolher uma jurisdição para o caso não solucionará a parte do litígio que diga respeito ao ordenamento jurídico preterido na definição da jurisdição, bem como a divisão do litígio de acordo com as diferentes jurisdições também será insuficiente para a tutela dos

3 Estes elementos de internacionalidade ("elemento di estrainetà") são um conceito central do processo internacional em sentido amplo.

\footnotetext{
${ }^{4}$ Christopher Whytock define "transnational litigation as litigation having connections to more than one country, and noting that these connections may be territorial when the activity or its effects touch the territory of more than one country, or based on legal relationships between a country and the actors engaged in or affected by that activity, such as citizenship".

${ }^{5} \mathrm{Na}$ América do Sul apenas o Brasil, a Argentina, o Uruguai, o Peru e o Chile detêm um modelo processual para a tutela de ações coletivas, mesmo assim o Brasil é o país que conta com a tutela mais ampla, sendo expressamente disciplinada em uma série de leis sobre o tema e aplicada pelo Poder Judiciário como um microssistema de normas que se interpenetram e subsidiam. As principais características da ação coletiva brasileira são sua atipicidade, qualquer espécie de ação ou tutela, seja condenatória, seja de obrigações de fazer e não fazer, e sua nãotaxatividade, quaisquer pretensões jurídicas coletivas, não se limitando aos direitos do consumidor ou ao direito ambiental.
} 
direitos, já que, muitas vezes, tratam-se de direitos indivisíveis como ocorre no direito ambiental e que não poderiam ser analisados segmentariamente, sob pena de prejuízo à recomposição do dano, dentre outras situações, para citar o caso do direito ambiental. Por isso, a cooperação jurídica internacional na modalidade de auxílio direito é importante instrumento a ser estudado nos litígios transfonteiriços.

\section{COOPERAÇÃO JURÍDICA INTERNACIONAL NA MODALIDADE DE AUXILIO DIREITO - UMA FORMA DE EVITAR DISPUTA ENTRE JURISDIÇÕES}

A cooperação internacional foi normatizada no NCPC nos arts. 26 a 41 e realiza-se através da homologação de sentença estrangeira, das cartas rogatórias e do auxílio direto, constituindo-se num sistema que inclui instrumentos tradicionais que perpassam pelo juízo de delibação exigível na relação entre órgãos jurisdicionais de diferentes ordenamentos jurídicos, que é o que ocorre nos pedidos homologação de sentença estrangeira e carta rogatória. Esta forma tradicional ainda está calcada no princípio da territorialidade da jurisdição, ínsito no princípio da soberania, pelo qual a jurisdição não pode extrapolar os limites de seu país (ZAVASKI, 2010).

Por outro lado, a cooperação internacional vai muito além do cumprimento de atos de natureza jurisdicional que necessitam do juízo de delibação pelo STJ, prevendo também uma forma mais moderna, que permite evitar limitações impostas por tais juízos delibatórios. Esta modalidade trata-se do auxílio direito, que iremos analisar a seguir.

O auxílio direto é forma de cooperação judicial internacional que independe de tramitação pela via diplomática e de juízo de delibação pelo Superior Tribunal de Justiça. Não haverá auxílio direto, se exigido exequatur do STJ.

Prevê o art. 30 do NCPC que será objeto do auxílio direto, além dos casos previstos em tratados que o Brasil faz parte: I - obtenção e prestação de informações sobre ordenamento jurídico e sobre processos administrativos ou jurisdicionais findos ou em curso; II - colheita de provas, salvo se a medida foi adotada em processo, em curso no estrangeiro, de competência exclusiva de autoridade judiciária brasileira; III - qualquer outra medida judicial ou extrajudicial não proibida em lei.

Como se percebe, a gama para utilização do auxílio direto alargou-se muito no NCPC, pois hoje, não apenas auxílio direto decorrente dos tratados é fundamento para sua utilização, 
como o novo código incluiu norma jurídica aberta no inciso III do art. 30, demonstrando ser este um abrangente instrumento para solução de questões no processo civil internacional que requerem maior coordenação entre ordenamentos jurídicos para a tutela dos direitos, como é o caso dos situações jurídicas que não respeitam fronteiras.

Nesse sentido, os litígios transfonteiriços, em virtude de, por suas características, serem afetos aos danos coletivos e ocorrerem simultaneamente em mais de um ordenamento jurídico, bem como serem comuns na matéria ambiental, cujos princípios norteadores são poluidor pagador e usuário pagador, a precaução/prevenção e a recuperação integral do dano e cuja característica é a ubiquidade, tornam-se matéria de grande complexidade no âmbito do processo internacional. Isso porque a adequada tutela dos direitos nos diferentes ordenamentos jurídicos envolvidos necessita ser pensada de forma estratégica para que ocorra efetivamente a tutela adequada dos direitos nos diferentes países, e não apenas em um deles, gerando parcialmente a recomposição do ilícito e resultando na quebra das premissas do poluidor pagador e da precaução/prevenção.

Em tais litígios, o auxílio direito é excelente instrumento para providências no âmbito da investigação, da prevenção e até mesmo da resolução dos litígios, e não exige prévia aprovação ou intermediação judicial entre diferentes ordenamentos jurídicos para serem executadas, geradoras, muitas vezes, de verdadeiros conflitos entre jurisdições, pois o auxílio direto é forma de cooperação que independe de tramitação pela via diplomática ou de juízo de delibação no STJ, conforme normatizado no art. 28 do NCPC.

A comunicação entre diferentes ordenamentos jurídicos para utilização do auxílio direto ocorre por meio de uma autoridade central (art. 29 do NCPC) estabelecida em cada um deles, que será responsável pelo trâmite burocrático dos pedidos de assistência em face de outro Estado-parte, tanto no que diz respeito à cooperação passiva (recebimento de pedidos), quanto à cooperação ativa (formulação de pedidos). A autoridade central age com respeito às normas de direito interno de cada Estado-parte, podendo recusar o auxílio, se incompatível com as normas de direito interno ou se incompatível com acordos internacionais relativos ao objeto em análise. Ela também pode realizar a adequada instrução dos pedidos, coordenando a sua execução com outras autoridades nacionais ou estrangeiras competentes. Poderá ocorrer o ajuizamento de medidas pela autoridade cooperante no seu próprio ordenamento, tendentes a garantir a efetividade judicial da tutela dos direitos, sem a necessidade de exequatur ou qualquer análise pelo tribunal local quanto ao "elemento di stranietá", pois superado. Litígios que não 
respeitam fronteiras, com ilícitos concomitantes, precisam de resposta enérgica, o mais homogênea e imediata possível.

O interessante é que, no auxílio direto, muitas providências podem ser produzidas sem autorização do Poder Judiciário, quando não possuírem natureza jurisdicional no âmbito interno, o que agiliza bastante o processo. Por outro lado, caso as providências solicitadas exijam autorização judicial, o Estado-parte requerido fica comprometido e autorizado a requerer junto aos órgãos jurisdicionais nacionais a medida necessária para tutela do direito em questão ${ }^{6}$. Nesse sentido, conforme previsto no art. 33 do NCPC, são o Ministério Público Federal e a Advocacia-Geral da União, os órgãos com capacidade postulatória para requerer, em nome do Estado brasileiro, perante o Judiciário, as medidas de cooperação internacional decorrentes do auxílio direto que, no âmbito interno, estão sujeitas à controle judicial. Por outro lado, quando se fala em cooperação jurídica internacional, não se trata apenas das modalidades existentes na área jurídica, sujeitas ao juízo de delibação perante o STJ, como o são a carta rogatória (art. 35 do NCPC) e a homologação de decisão estrangeira (arts. 960 a 965 do NCPC), mas também da modalidade de auxílio direto extrajudicial previsto no NCPC, art. 28 ao 34, além dos casos de auxílio direto previstos em tratados de que o Brasil é signatário.

Dessa forma, não há como olvidar que a cooperação jurídica internacional, na modalidade de auxílio direto, é impactante para a consecução dos novos objetivos vigentes no NCPC, seja no âmbito nacional, seja no âmbito internacional, pois a tutela dos direitos adequada, tempestiva e efetiva (art. $4^{\circ}$ e $6^{\circ}$ do NCPC), constantes do Capítulo 1 - Das Normas Fundamentais do Processo Civil, é norma que abrange todo o sistema processual.

Portanto, no processo internacional transfronteiriço, muito mais relevante que colocar as questões apenas sob a perspectiva do processo internacional clássico, o qual exige, comumente, a realização dos juízos de delibação das diferentes jurisdições, é analisar, em abstrato, qual seria a melhor estratégia para tutelar os direitos envolvidos com a solução efetiva dos problemas, e, após isso, optar pelos instrumentos mais adequados para a efetivação dos direitos.

Nesse sentido, a utilização do auxílio direito é forma inteligente de encurtar caminhos, produzir provas de forma conjunta nos ordenamentos jurídicos envolvidos, bem como buscar a tutela dos direitos diretamente no âmbito interno por meio das autoridades centrais, transformando questões que antes eram de direito internacional privado e sujeitas ao "elemento

\footnotetext{
${ }^{6}$ Recl. 2.645, rel. Min. Teori Albino Zavascki, Corte Especial, STJ, j. 18/11/2009.
} 
di straneità" em questões de direito interno, permitindo ainda que tais tutelas ocorram de forma simultânea nos diferentes ordenamentos como faz-se necessário, muitas vezes, nos casos dos litígios transfonteiriços.

\section{CONCLUSÕES E PROBLEMAS A SEREM RESOLVIDOS NO FUTURO}

A cooperação jurídica internacional e o auxílio direto normatizados no NCPC representam grande avanço no processo internacional transfronteiriço. Refletem a passagem do processo civil clássico, do Estado Liberal, jurisdição igual soberania, para as preocupações do direito processual no Estado Democrático Constitucional, no qual o processo serve à tutela dos direitos, tempestiva, adequada e efetiva.

Nos litígios coletivos transfronteiriços, a ausência de uniformidade acerca dos institutos que caracterizam as demandas coletivas torna a temática dos danos ambientais transfronteiriços uma matéria de extrema complexidade.

Exemplos de elementos internacionais que são problemas a serem resolvidos são: (1) a existência de jurisdições concorrentes (LUPOI, 2002, p. 4-5)7 ; (2) a patologia das decisões duplicadas ou conflitantes (LUPOI, 2002, p. 6); (3) a distinção entre os vários modelos de direito material e processual aplicáveis à resolução da matéria; (4) a frustração processual da necessidade de tutela pelas deficiências do direito interno.

Um dos problemas mais relevantes é justamente o fato de que nem sempre os Estadosnação afetados são dotados de instrumentos processuais disponíveis para a tutela daquele direito/pretensão em matéria ambiental. Há uma consequente ausência de tutela ou, em alguns casos, uma sobreposição de tutelas, que precisa ser coordenada pela boa dogmática processual de maneira a servir o processo como meio para a tutela dos direitos, seu principal fim.

O ideal seria atingir uma harmonia entre os instrumentos processuais e as necessidades de tutela de direitos materiais (expressamente reconhecidos ou não), de forma a permitir que, mesmo nos locais em que não haja instrumentos suficientes para tutela de determinado direito

\footnotetext{
${ }^{7}$ Lupoi, ao tratar do tema jurisdição, coloca o foco no conflito e nos litigantes, por isso refere que é absolutamente correto falar, não somente em conflito de jurisdições, mas também em jurisdições em contraste e concorrentes.
} 
(material ou processual), o reconhecimento das decisões tomadas pelas jurisdições concorrentes ocorresse de forma a assegurar os direitos.

Entretanto, como o ideal ainda está longe, a cooperação jurídica internacional na modalidade de auxilio direito é eficiente forma de evitar o conflito entre jurisdições e obter a tutela dos direitos adequada porque ocorre de forma mais inteligente ao utilizar as autoridades centrais e o próprio direito interno como órgãos intermediadores em busca da tutela do direito material versado no litígio; tempestiva porque ocorre de forma que a tutela venha em tempo razoável, por utilizar autoridades centrais, encurtando caminho entre os diferentes órgãos das jurisdições envolvidas; e efetiva porque ocorre de forma mais abrangente e simples para a realização dos direitos no mundo real, ao permitir que se busque a tutela em diferentes jurisdições sem discutir competência internacional e tantos outros problemas decorrentes do processo internacional e da escolha do direito aplicável. Evita-se o conflito entre jurisdições e possibilita-se a tutela dos direitos de forma simultânea entre as diferentes jurisdições envolvidas, o que permite melhor tutela dos litígios que não respeitam fronteiras.

\section{REFERÊNCIAS BIBLIOGRÁFICAS}

BASSET, Debra Lyn. U.S Class Action Go Global: Transnational Class Actions and Personal Jurisdiction. In: Fordham Law Review. v. 72 (1), 2003.

CHIOVENDA, Giuseppe. Instituições de direito processual civil. Vol. II. Trad. J. Guimarães Menegal e notas de Enrico Tullio Liebman. São Paulo: Saraiva, 1943 [Istituzioni di Diritto Processuale Civile, 1933/1934].

DIDIER JR., Fredie; ZANETI JR., Hermes. Curso de Processo Civil. Processo Coletivo. 9. ed. Salvador: JusPodivm, 2014. v. 4. p. 38/39.

FERRER CORREIA, António. Lições de Direito Internacional Privado I, Almedina: Coimbra, 2000 .

GIDI, Antonio. A class action como instrumento de tutela coletiva de direitos. São Paulo: RT, 2007.

GRINOVER, Ada Pellegrini; WATANABE, Kazuo; MULLENIX, Linda. Os processos coletivos nos países de Civil Law e de Common Law. 2. ed. São Paulo: RT, 2014.

JOSEPH, Sarah. Corparations and Transnational Human Rights Litiation. Oxford: Hart, 2004.

KRAMER, Xandra E.; RHEE, C.H. van (ed). Civil Litigation in a Globalising World. Hague: Springer, 2012;

LIMA PINHEIRO, Luís de. Direito Internacional Privado III: Competência Internacional e Reconhecimento de Decisões Estrangeiras, Almedina: Coimbra, 2002.

LIMA PINHEIRO, Luís de. Direito Internacional Privado I: Introdução e Direito de Conflitos - Parte Geral, Almedina: Coimbra, 2001. 
LUPOI, Michele Angelo, Confliti Transnazionali di Giurisdizioni, Tomo I, Giuffrè: Milão, 2002.

MARINONI, Luiz Guilherme. Curso de Direito Processual Civil. São Paulo: RT, 2006.

MENDES, Aluisio Gonçalves de Castro. Ações coletivas no direito comparado e nacional. São Paulo: RT, 2002.

MESQUITA, José Ignácio Botelho de. Da competência internacional e dos princípios que a informam. Revista de Processo, n. 50, São Paulo: Saraiva, 1988.

MITIDIERO, Daniel. A Tutela dos Direitos como Fim do Processo Civil no Estado Constitucional. Revista de Processo, ano 39, v. 229, março, 2014.

MONESTIER, Tanya J. Transnational Class Actions and the illusory search for Res Judicata. In: Tulane Law Review. Rev.1. 2011;

MOSCHEN, Valesca Raizer Borges; GUERRA, Marcel Victor M., Processo Civil Transnacional: A Caminho de uma Sistematização dos Princípios de Competência Internacional: Reflexos de um Novo Paradigma Axiológico Face à Crise Metodológica Positivista, In: Anais do XVIII Encontro Nacional do CONPEDI, Fundação Boiteux, 2009.

MOSCHEN, Valesca Raizer Borges; LOMEU, Mariana. A Análise Jurisprudencial da Competência Internacional Brasileira: Uma Reflexão à Luz da Experiência Comparada e da Arbitragem. In.: MENEZES, Wagner; MOSCHEN, Valesca Raizer Borges. CONPEDI/UNINOVE. Florianópolis: FUNJAB, 2013, www.compedi.org.br, publicações, acesso em 18.01.2016;

MOSCHEN, Valesca Raizer Borges; ZANETI JR., Hermes. A autonomia da vontade como expressão democrática do exercício jurisdicional: a cláusula de eleição de foro na harmonização jurídica multilateral e regional e no Código de Processo Civil brasileiro de 2015. No prelo.

PERLINGEIRO, Ricardo. Eficácia da Jurisdição Externa. Niterói: Eduff, 2014.

QUEIRÓ, Afonso Rodrigues. Prefácio à $2^{\mathrm{a}}$ ed. portuguesa, pp. VIII, In: BRIERLY, James Leslie. Direito Internacional, Trad. M. R. Grucho de Almeida, 4 ed., Lisboa. Fundação Calouste Gulbenkian, 1979.

SILVA NETO, Orlando Celso da. Direito Processual Civil Internacional Brasileiro. São Paulo: LTr, 2003.

UZELAC, Alan (ed). Goals of Civil Justice and Civil Procedure in Contemporary Judicial System. Dordrecht: Springer, 2014.

VON BAR. Christian. Environmental damage in Private International Law. In: Recueil des Cours. v. 268, La Haye: Académie de Droit International de la Haye, Martinus Nijhoff Publishers, 1999.

WHYTOCK, Christopher A.. The Evolving Forum Shopping System, CORNELL L. REV. 481, 486 (2011).

ZANETI JR., Hermes; BORGES, Orlindo Francisco; CARDOSO, Juliana Provedel. Ações Coletivas Transnacionais para Tutela de Danos Ambientais: Caso CHEVRON (STJ, HSE N 
8.542). No Prelo.

ZAVASKI, Teori Albino. Cooperação Jurídica Internacional e a concessão de Exequatur, Revista de Processo, V. 35, nº 183, maio, 2010. 